Casos Clínicos

Arch. Esp. Urol. 2010; 63 (9): 808-811

\section{LEIOMIOMA DE LA CÁPSULA RENAL: PRESENTACIÓN DE UN CASO}

Juan Carlos Ramírez Fernández, Zaki Mohamed Mohamed, Javier Casado Varela, Jesús Salinas Casado, Ricardo Wert Ortega' y Miguel Angel García-Cabezas².

Unidad de Urología y Litiasis, Unidad de Radiodiagnóstico' y Servicio de Anatomía Patológica² (CitoPath, S.L.). Hospital Ruber Internacional. Madrid. España.

Resumen.- OBJETIVO: Presentamos un caso de leiomioma de la cápsula renal en una mujer de 49 años que fue encontrado de manera incidental durante un estudio ecográfico abdominal por reflujo gastroesofágico. A partir de este caso discutimos el diagnóstico clínico, radiológico y anatomopatológico de los leiomiomas renales así como su tratamiento.

MÉTODOS: La paciente fue estudiada mediante ecografía, TC y RM. Tras la nefrectomía radical se realizó el estudia anatomopatológico convencional de la pieza quirúrgica incluyendo técnica inmunohistoquímica.

\section{CORRESPONDENCIA}

M. A. García-Cabezas

Servicio de Anatomía Patológica

(CitoPath, S.L.)

Hospital Ruber Internacional

La Masó, 38

Mirasierra 28034 Madrid (España).

garcia.cabezas@uam.es

Aceptado para publicar: 5 de febrero 2010.
RESULTADO: Ecográficamente se detectó una masa sólida, hipoecoica y pobremente vascularizada en el polo superior del riñón derecho. La TC y la RM detectaron una masa bien delimitada de densidad de partes blandas sin afectación local o regional y sin adenopatías. Se realizó una nefrectomía radical. Microscópicamente la masa estaba constituida por una proliferación fusocelular de bajo grado cuyas células se marcaban con anticuerpos contra antígenos de músculo liso. La masa estaba en continuidad con la cápsula renal y comprimía ligeramente el parénquima renal sin producir lesiones relevantes en él.

CONCLUSIONES: Los leiomiomas renales son tumores infrecuentes que se deben sospechar ante mujeres jóvenes o de edad media con tumores renales asintomáticos, bien delimitados, hipoecoicos y con densidad de partes blandas en la TC. Si no hay afectación de estructuras vasculares, se podría optar por una intervención quirúrgica conservadora. Microscópicamente son tumores fusocelulares de bajo grado con el perfil inmunohistoquímico típico de los tumores del músculo liso.

Palabras clave: Leiomioma. Riñón. Cápsula renal. Fusocelular. Tumor benigno.

Summary.- OBJECTIVE: We present a case of leiomyoma of the renal capsule in a 49 year-old woman that was detected incidentally during an abdominal study for gastroesophageal reflux. We discuss the clinical, radiological and pathological diagnosis of renal leiomyoma as well as its treatment alternatives.

METHODS: Ultrasonography, CT and MRI were performed. A conventional pathological analysis including immunohistochemistry was performed after radical nephrectomy.

RESULTS: Ultrasonography detected a solid hypoechoic mass poorly vascularized in the upper pole of the right kidney. CT and MRI detected a well-delimited mass showing soft tissue density without extension to the neighbor structures and without lymphadenopathies. Radical nephrectomy was performed. Microscopically, the mass was made of a low-grade fusocellular proliferation with cells staining with antibodies against smooth muscle markers. The mass was in continuity with the renal capsule and compressed slightly the renal parenchyma without damaging it.

CONCLUSIONS: Renal leiomyomas are unfrequent benign tumors that should be suspected in young and middle aged women showing asymptomatic, well delimited and hypoechoic renal tumors with soft tissue density in CT scans. When vascular structures are not involved by the tumor, a conservative surgical intervention could be the first therapeutic option. Microscopically, renal leiomyomas are low-grade fusocellular tumors showing a smooth muscle immunohistochemical profile. 
Keywords: Leiomyoma. Kidney. Renal capsule. Spindle-cell. Benign tumor.

\section{INTRODUCCIÓN}

Los leioimiomas del riñón son neoplasias poco frecuentes, en su mayoría asintomáticas, habiéndose publicado hasta la fecha menos de 40 casos que presentasen síntomas y requiriesen tratamiento quirúrgico (1-3). Sin embargo su detección como nódulos asintomáticos en la autopsia puede llegar al 5\% (4). En los estudios por imagen aparecen como lesiones bien delimitadas, hipoecoicas en la ecografía y de densidad equivalente a las partes blandas en la TC $(1,2,5,6)$.

El diagnóstico anatomopatológico puede plantear dudas con otros tumores fusocelulares de bajo grado, frecuentes en el retroperitoneo, como los neurofibromas y schwannomas, siendo de ayuda los marcadores inmunohistoquímicos del músculo liso como la desmina y la actina específica de músculo liso (7).

Presentamos un caso de leiomioma de la cápsula renal, detectado casualmente en un estudio ecográfico abdominal y discutimos su diagnóstico clínico, radiológico y anatomopatológico, así como su tratamiento.

\section{CASO CLÍNICO}

Paciente mujer de 49 años de edad en estudio por reflujo gastroesofágico que en la ecografía - doppler abdo-

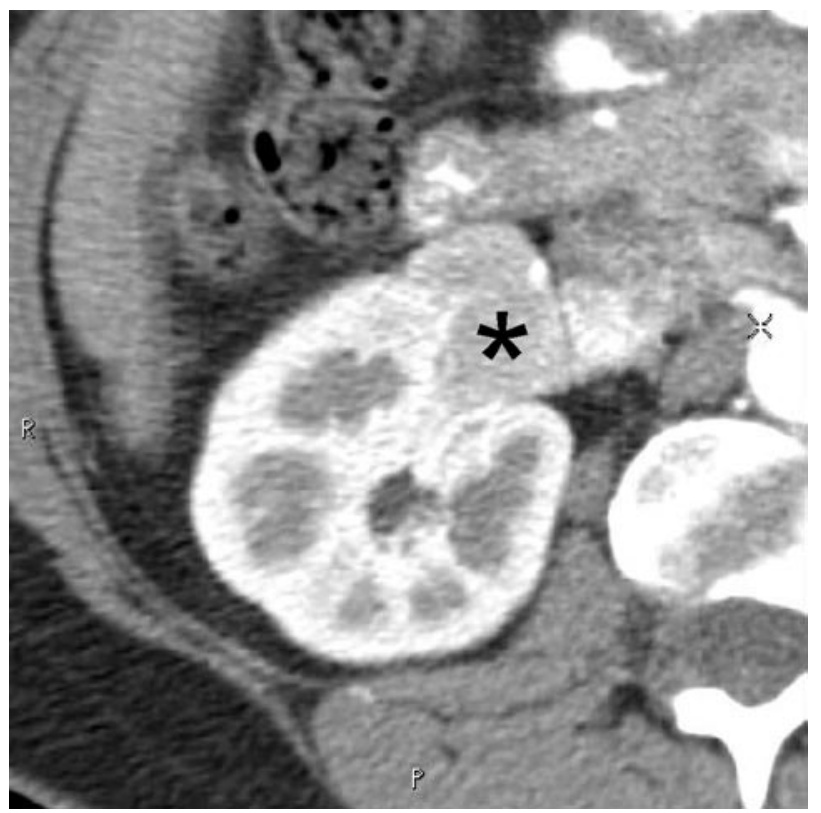

FIGURA 1. Imagen de TC donde se observa una masa (asterisco) en el borde anteromedial del riñón derecho, bien delimitada y con densidad de partes blandas. minal presentó una masa sólida en el riñón derecho, hipoecoica y pobremente vascularizada. No se anotaron hallazgos relevantes en la exploración física.

En la TC toracoabdominopélvica se observó una masa en el borde anteromedial del riñón derecho, cerca del polo superior, bien delimitada, con densidad de partes blandas, que desplazaba la vena renal sin interrumpir su flujo (Figura 1, el tumor está marcado con un asterisco). En la RM de abdomen se detectó la presencia de una tumoración exofítica dependiente del polo superior del riñón derecho, de $3^{\prime} 5 \mathrm{~cm}$ de diámetro, de contorno bien definido, en íntimo contacto con la vena renal derecha y la vena cava inferior, con intensidad intermedia tanto en $\mathrm{T} 1$ como en T2 realzando en la fase arterial pero en menor grado que el parénquima renal adyacente. En la fase intersticial y venosa la lesión era hipointensa con respecto al parénquima renal.

Con el diagnóstico de masa renal derecha se realizó una nefrectomía radical mediante abordaje por lumbotomía. No se optó por una nefrectomía parcial debido a la localización de la masa y la posible implicación vascular.

La pieza quirúrgica pesó 209 gramos en fresco y midió $10 \times 5^{\prime} 5 \times 4$ centímetros. Adherida a la cápsula renal próxima al polo superior se identificó una masa polinodular de 3 centímetros de diámetro máximo, que al corte era sólida, bien delimitada, blanquecina, fasciculada y de consistencia fibrosa. Microscópicamente el tumor estaba constituido por células fusiformes con núcleos en forma de cigarro puro y citoplasma eosinó-

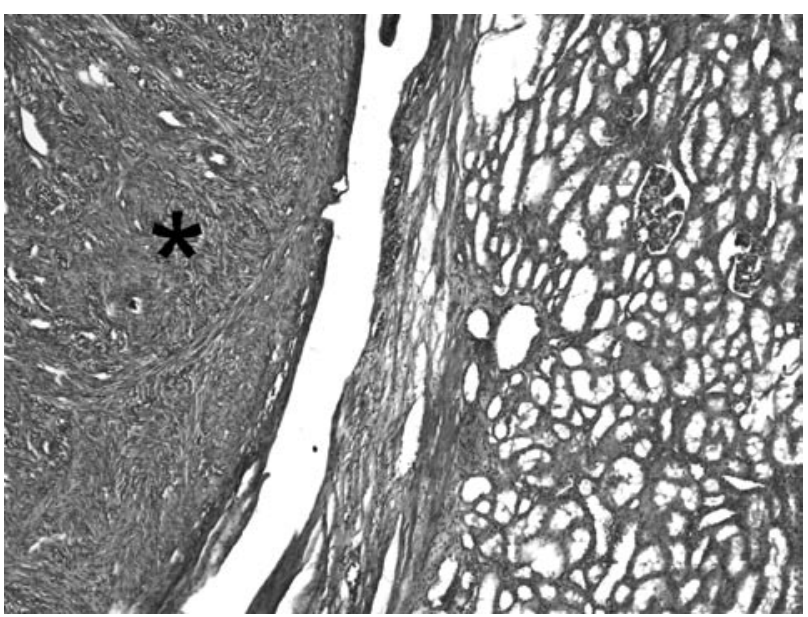

FIGURA 2. Corte histológico teñido con hematoxilina y eosina en el que se observa un tumor (asterisco) constituido por células fusiformes dispuestas en fascículos con distintas orientaciones en el espacio tridimensional. El tumor está en continuidad con la cápsula renal comprimiendo el parénquima renal. 
filo, que se disponían en fascículos con distintas orientaciones en el espacio tridimensional. No se encontraron atipias celulares, mitosis, ni focos de necrosis. El tumor estaba en continuidad con la cápsula renal, comprimiendo el parénquima renal y desplazando la vena renal sin infiltrar las estructuras vecinas (Figura 2, el tumor está marcado con un asterisco). Con técnica inmunohistoquímica las células fusiformes se marcaron con anticuerpos contra actina del músculo liso y no lo hicieron con anticuerpos contra CD117, proteína $S$ 100 y HMB-45. El índice mitósico estimado con anticuerpos contra Ki-67 fue inferior al 1\%. El diagnóstico anatomopatológico fue de leiomioma de la cápsula renal.

\section{DISCUSIÓN}

El leiomioma es una neoplasia benigna que se puede originar en todas aquellas estructuras del aparato genitourinario que contengan músculo liso (3). Los leiomiomas renales se originan con mayor frecuencia en la cápsula renal $(90 \%)$; el $10 \%$ restante proceden de la pelvis renal y los vasos renales (8). Algunos autores piensan que podrían originarse en las células epitelioides perivasculares ("perivascular epithelioid cells", $P E C)$, que originan los angiomiolipomas y se marcan con anticuerpos contra HMB-45 (nuestro caso no lo hizo) (7).

Epidemiológicamente, los leiomiomas renales presentan una mayor incidencia en la raza blanca $(70 \%)$ y las mujeres $(66 \%)$, sobre todo entre la $2^{\underline{a}}$ y la $5^{\underline{a}}$ década de la vida, con una edad media de aparición de 42 años. No se ha descrito ninguna predilección por el riñón derecho o el izquierdo, aunque sí un mayor predominio de aparición en el polo inferior del riñón (74\%) (1).

Desde el punto de vista clínico suelen ser masas asintomáticas. El signo clínico más frecuente es la presencia de masa palpable $(57 \%)$ asociado o no a dolor en flanco (53\%); la triada clásica de Guyon, consistente en la aparición de hematuria, dolor y masa abdominal, se encuentra solamente presente en el $3{ }^{\prime} 3 \%$ de los casos (1). El hallazgo de leiomiomas de gran tamaño, clínicamente sintomáticos, es excepcional (9). En la revisión de Steiner y cols. hasta 1989 el tumor más grande medía 57 centímetros con un promedio de $12^{\prime} 3$ centímetros (1). Por lo general, estos tumores se suelen diagnosticar en la autopsia, con una frecuencia que oscila entre el $4^{\prime} 2 \%-5{ }^{\prime} 2 \%$ (4).

En los estudios por imagen los leiomiomas no presentan ninguna característica específica que los diferencie de otras masas. Ecográficamente son lesiones sólidas bien delimitadas e hipoecoicas en su mayor parte. La TC, más sensible que la ecografía, suele mostrar una lesión sólida, en contacto con la cápsula o la pelvis sin signos de afectación local o regional y con una densidad radiológica similar a la de partes blandas. La presencia de invasión de estructuras vecinas sugiere que se trate de un leiomiosarcoma. Aunque en su mayoría son lesiones sólidas (73\%), también pueden formar masas quísticas o mixtas sólidas y quísticas $(1$, $2,5,8,10)$.

En nuestro caso, dada la falta de especificidad de los estudios de imagen, la localización de la masa, la posible afectación vascular y la sospecha de que se tratase de un tumor maligno hizo que se optase por la cirugía radical. Sin embargo, algunos autores plantean que se puede realizar una intervención conservadora en casos seleccionados si radiológicamente el tumor muestra las características ya descritas y no infiltra estructuras del pedículo vascular renal $(1,10)$.

Desde el punto de vista anatomopatológico, los leiomiomas renales son masas sólidas, blanquecinas, bien delimitadas y de consistencia fibrosa pudiendo mostrar áreas quísticas y hemorrágicas. La presencia de necrosis y de invasión de estructuras adyacentes es propia de los leiomiosarcomas. Microscópicamente son tumores constituídos por células fusiformes dispuestas en fascículos entrelazados, de citoplasma eosinófilo y núcleo con forma de cigarro puro sin atipia citológica. El índice mitósico suele ser muy bajo. Los principales diagnósticos diferenciales se plantean con otros tumores retroperitoneales fusiformes de bajo grado, como los schwanomas y neurofibromas e incluso los tumores del estroma gastrointestinal, siendo muy útiles los marcadores inmunohistoquímicos: los leiomiomas se marcan con anticuerpos contra antígenos musculares, como la actina específica de de músculo liso y la desmina, y no lo hacen con anticuerpos contra proteína S-100, que marca tumores de la vaina neural, ni contra CD 117 (c-kit), que marca los tumores del estroma gastrointestinal.

El diagnóstico diferencial también hay que establecerlo con los angiomiolipomas renales muy ricos en células musculares lisas: es necesario estudiar múltiples cortes histológicos para detectar la presencia de tejido adiposo o de vasos anómalos en el seno del tumor, lo que confirmaría que se trata de un angiomiolipoma; estos últimos, originados en células PEC, se marcan con anticuerpos contra HMB-45, aunque hay que recordar que algunos leiomiomas de la cápsula renal también lo hacen.

Finalmente, los criterios anatomopatológicos para diferenciar un leiomioma de un leiomiosarcoma no están establecidos con la misma precisión que en otros órganos. La presencia de atipia nuclear y pleomorfismo citológico no es suficiente para diagnosticar un leiomiosarcoma y no hay una cifra de índice mitósico establecida por encima de la cual se diagnostique este tumor maligno; sin embargo, estos tres criterios junto con la presencia de invasión vascular y de necrosis sí justifican el diagnóstico de leiomiosarcoma (7). 


\section{CONCLUSIONES}

Los leiomiomas renales son tumores infrecuentes, muchas veces asintomáticos que carecen de hallazgos radiológicos patognomónicos. Sin embargo, se debe sospechar su presencia ante mujeres jóvenes o de edad media con tumores renales asintomáticos, bien delimitados, hipoecoicos y con densidad de partes blandas en la TC. En estos casos, y si no hay afectación de estructuras vasculares, se podría optar por una intervención quirúrgica conservadora. Microscópicamente son tumores fusocelulares de bajo grado con el perfil inmunohistoquímico típico de los tumores del músculo liso.

\section{BIBLIOGRAFIA y LECTURAS RECOMENDADAS (*lectura de interés $y^{* *}$ lectura fundamental)}

**1. Steiner M, Quilan D, Goldam SM, Millmond S, Hallowell MJ, Stutzman RE. et al. Leiomyoma of the kidney: presentation of 4 new cases and the computerized tomography. J.Urol, 1990; 43: 994-998.

**2. Cortadellas AR, Castellanos Acosta RI, Guzmán Fernández A, Pérez Herms S, Munne A, Benkirane H. et al. Leiomioma de cápsula renal. Presentación de un caso y revisión de la literatura. Arch.Esp.Urol, 1992; 45: 478-480.

**3. Belis J, Post G y Rochman S. Genitourinary leiomyomas. Urol, 1979; 13: 424-429.

*4. Xipell J M. The incidence of benign renal nodules (a clinicopathologic study). J.Urol, 1971; 106: 503506.

**5. Selli C, Masi A y Vanni L. Conflicting aspects of renal leiomyoma with different imaging techniques. Urol.Int, 1992; 48: 219-222.

**6. Protzel C, Woenckhaus C, Zimmermann U y Klebingat $\mathrm{K}$ J. Leiomyoma of the kidney. Differential diagnosis aspects of cell carcinoma with increasing clinical relevance. Urologe, 2001; 40: 384-387.

**7. Bostwick D y Cheng L. Urologic Surgical Pathology. Páginas: 77-173. Mosby-Elsevier; $2^{\mathrm{a}}$ edición, 2008.

*8. Montoya Lirola MD, García Tabar PJ, Gutiérrez Díez JM, Ateca Díaz-Obregón R, Berreteaga GallasteguiJR y Peña Arza, M. El leiomioma renal sintomático. Arch.Esp.Urol, 1993; 46: 833-835.

*9. Nagar AM, Raut AA, Narlawar RS, Bhatgadde VL, Rege S y Thapar V. Giant renal capsular leiomyoma: study of two cases. Br.J.Radiol, 2004; 77: 957-958.

*10. Clemente Ramos CM, Candia Fernández A. y Allona Almagro A. Leiomioma renal sintomático: una masa renal de difícil diagnostico. Actas.Urol.Esp, 2003; 27: 546-550.

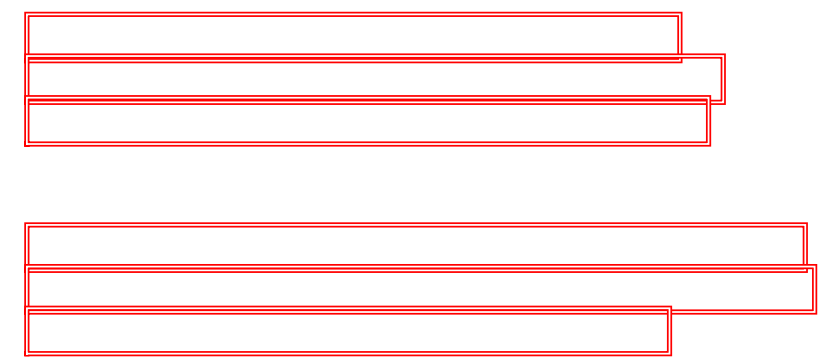

